Mitteilungen der Deutschen Gesellschaft fir Phlebologie

\title{
AG Thrombose:
}

Vorankündigung DGP 2020 - Leipzig -

\section{Dr. Tobias Hirsch}

Für das Jahr 2020 ist Dr. Tobias Hirsch der Held der Stunde - dank seiner außerordentlichen Flexibilität hat er seine Option um einige Jahre vorgezogen, als es zur geplanten Tagung in Aachen aus Termin-Überschreitungsgründen nicht kommen konnte. Dafür sei noch einmal der besondere Dank der Gesellschaft ausgesprochen. Wir dürfen uns auf die nächste Jahrestagung der DGP in Leipzig vom 02.-05.09.2020 freuen! 